\title{
PCR for Screening Potential Probiotic Lactobacilli for Piglets
}

\author{
Maurilia Rojas-Contreras ${ }^{1}$, \\ María Esther Macías-Rodríguez ${ }^{2}$ and José Alfredo Guevara Franco ${ }^{1}$ \\ 1 Universidad Autónoma de Baja California Sur, \\ Área de Conocimientos Ciencias Agropecuarias, Food Science and Technology Laboratory, \\ La Paz, Baja California Sur, \\ ${ }^{2}$ Universidad de Guadalajara, Centro Universitario de Ciencias e Ingenierías, \\ Department of Pharmacobiology, Sanitary Microbiology Laboratory, Guadalajara, Jalisco, \\ México
}

\section{Introduction}

\subsection{Screening of potential probiotic lactobacilli}

To continuously select probiotic bacteria, is needed to look for new strategies to make easy this task. In this chapter the characterization and identification by PCR of presumptive adhering lactobacilli to piglet gastrointestinal tract components is described and compared with previous reports. Lactobacillus is one of the major bacterial groups in the gastrointestinal tract of humans and animals (Smith, 1965; Dubos, 1965). Moreover, there is accumulating scientific evidence which strongly suggest that lactobacilli are associated with health (Bibel, 1988; Sanders, 2011). Consequently lactobacilli are frequently used as probiotics. This term refers to preparations of living microbes that can be added to the diet to improve health in humans and in farm animals (Fuller, 1989; Guilliland et al., 2001). The number of reports of health-promoting effects attributed to Lactobacillus strains has been increased in recent years where antagonistic activities against enteropathogens and modulation of immune system are well documented (Collado, 2006). The worldwide impact of advances in the scientific knowledge in this area is being enormous. For instance, diarrheal diseases affect millions of people throughout the world, having the greatest impact among children in developing countries (Guerrant et al., 1990; Guarino et al., 2011; Mondal et al., 2011). Lactobacillus have been shown to possess inhibitory activity toward the growth of pathogenic bacteria such as Listeria monocytogenes (Ashenafi 2005; Harris et al., 1989), Escherichia coli, Salmonella spp. (Chateau \& Castellanos, 1993; Hudault et al., 1997), and others (Coconnier et al., 1997). When lactobacilli could be commonly used to prevent or alleviate some of the infections by enteropathogens, e. g. E. coli, Salmonella, Shigella, Campylobacter, etc. it could be an achievement for human beings. From an economical point of view, lactobacilli could reduce the risk for major economic losses due to decreased performance and health in the farm industry. For example, pig rising has become more industrialized and intestinal disturbances, e. g. diarrhea, affect significantly the piglet health and decrease intestinal performance (Goswami et al., 2011; Oostindjer et al., 2010). 
Antibiotics have been used successfully against these infections, however there is an increasing concern consuming meat containing antibiotic residues as well as the potential hazards from spreading of resistance factors. Lactobacilli Lactobacillus is an alternative to maintain the health of growing pigs, mainly were environmental conditions are not controlled (Chiduwa et al., 2008). Under these conditions are a large number of pig farms worldwide. These conditions stress the animals, causing susceptibility to gastrointestinal diseases. It is well known that lactobacilli is a habitant of the intestinal tract of pigs and has been found as dominant microbiota. However confinement in small yards, large variations in temperatures, diet and other conditions, stress the animals, causing susceptibility to gastrointestinal diseases (Shimizu \& Shimizu, 1978). Lactobacilli should retain special features to survive under these harsh conditions. At birth, piglets are exposed to a huge variety of microorganisms. Most of them come from the vagina, faeces, and skin of the mother as well as the environment (Jonsson \& Conway, 1992). Composition of gut microbiota can be modulated by host, environmental, and bacterial factors (ThompsonChagoyán et al., 2007). The colonization potential of lactobacilli has been investigated using small intestinal mucus extracts from 35 day old pigs. Numbers of lactobacilli in different portions of the small intestine of 35 days old pigs were enumerated. Mucus isolated from the small intestine of pigs was investigated for its capacity to support the growth of lactobacilli and results confirmed that Lactobacillus spp inhabit the mucus layer of the small intestine and can grow and adhere to ileal mucus (Rojas \& Conway, 1996). The survivability and colonization of probiotics in the digestive tract are considered critical to ensure optimal functionality and expression of health promoting physiological functions. Muralidhara (Muralidhara, 1977) reported that viable counts of lactobacilli in tissue homogenates from the duodenum and upper jejunum of 3 weeks old pigs were 5.5-6.21 $\log _{10}$ per $g$ mucosa. In addition, when segments of the small intestine of piglets, from the duodenum to the ileum were examined, it was found that lactobacilli increased from 6.4 to $8.2 \log _{10}$ per $g$ of mucosa (McAllister et al., 1979). From the total numbers of identified strict anaerobic organisms associated with the cecal mucosa, anaerobic lactobacilli were much lower (4.0-5.7 $\left.\log _{10}\right)$ per $\mathrm{cm}^{2}$ than the numbers of obligated anaerobes. Although differences in the counts of the different groups of organisms have been quite large for the various reports, Lactobacillus appears to be dominant group in cecal and colonic content.

Screening for functional and probiotic attributes in lactobacilli new isolates is commonly performed, following these assays: Gram stain, acid and bile salt tolerance, cell surface hydrophobicity, adhesion to mucus and mucin, autoaggregation, Caco- 2 cell-binding as well as antibacterial activity against E. coli, L. monocytogenes, S. typhi, etc. and antioxidative activities (Jacobsen et al., 1999; Macías-Rodríguez et al., 2008; Kaushik et al., 2009). Recently a screening of predominant Lactobacillus strains from healthy piglets has been performed in order to select specific probiotics for arid land piglets. Among the 164 isolates, 27 adhesive strains were identified using comparisons with $16 \mathrm{~S}$ rDNA and intergenic 16-23S sequences. Results indicated that L. fermentum and L. reuteri were the most common species in faeces and mucus, respectively (Macías-Rodríguez et al., 2009). Likewise probiotics are increasingly used as nutraceuticals, functional foods or prophylactics and considering that probiotics strains have shown to be populationspecific due to variation in gut microbiota, food habits and specific host-microbial interactions (Kaushik et al., 2009), screening of new indigenous probiotic strains in different region of the world is necessary. 


\subsection{Colonization by lactobacilli}

Colonization studies of lactobacilli to the gastrointestinal tract first were concentrated on the attachment to the non secretory epithelium from the stomach. Cell morphology by electron microscopy, viable counts and biochemical test have been very important tools to identify lactobacilli attached to the keratinized squamous epithelium of the stomach of mice $(\mathrm{N}$. Suegara et al., 1975; Moser \& Savage, 2001; Savage, 1992; Tannock \& Savage, 1974; Conway \& Adams, 1989) and pig (Fuller et al., 1978; Pedersen \& Tannock, 1989; Tannock et al., 1987; Henriksson et al., 1991). Later other reports on colonization by lactobacilli to other regions in the intestinal tract were found. Colonization of lactic acid bacteria isolated from rats and humans in the gastrointestinal tract of gnotobiotic rats has been studied by performing viable counts of the contents and tissue homogenates from the different regions of the intestinal tract. It was observed that lactobacilli seem to be retained, and to multiply on the mucosal surfaces along the intestinal tract (Kawai et al., 1982). In other report lactobacilli were ingested by human volunteers and samples of jejunal fluid at varying intervals were cultured for lactobacilli (Robins-Browne \& Levine, 1981). It was shown that lactobacilli entered the small intestine and persisted there for 3-6 h after which time, levels returned to the base-line (Dixon, 1960). Studies on the possible interaction of lactobacilli with mammalian extracellular proteins have been performed. It was shown that specific collagen binding is common among lactobacilli of various origins (Aleljung et al., 1991).

Attention has been focused on interactions of lactobacilli with the mucosa of the intestinal tract. The gastrointestinal tract is covered by a protective mucus layer consisting of glycolipids and a complex mixture of large and highly glycosylated proteins called mucins as the main components. Mucus layer represents the first barrier of contact between bacteria contained in the lumen and the epithelial cell layer of the host (Tassell et al., 2011). Ability of commensal bacteria to adhere mucus is an important characteristic that is evaluated in probiotic bacteria (Ma et al., 2005). Adherence of lactobacilli to the intestinal epithelium and mucus is associated with stimulation of the immune system and inhibition of adhesion of pathogens (Herías et al., 1999). Caco-2 and HT-29 cells and a subpopulation of mucus secreting HT29-MTX cells have been used to study the adhesion of human isolated $L$. acidophilus BG2F04 strain. These studies showed scanning electron micrographs where mucus secreting HT29-MTX monolayer covered by the dense mucus gel produced by these typical goblet cells, bound to lactobacilli. In addition they proposed a model for the adherence of this Lactobacillus strain to human intestinal cells (Coconnier et al., 1997). Other workers used human colon mucosa in an in vitro assay, to test the capacity of five Lactobacillus strains to colonize; a dense population of lactobacilli was observed covering the whole mucosal surface of the colon tissue (Sarem-Daamerdji et al., 1995). Other contributions for understanding the interactions between gastrointestinal mucosa and lactobacilli have been reported. The diversity of Lactobacillus spp on healthy and diseased human intestinal mucosa biopsies has be studied (Molin, 1993). These workers assessed the potential of the Lactobacillus isolates for treating intestinal disorders, suggesting that there are no general differences in the type of dominating Lactobacillus microbiota between mucosa from different regions of the intestine. In another report, different Lactobacillus strains in fermented oatmeal soup were administered to healthy human volunteers. Biopsies were taken from both the upper jejunum region and the rectum before one and eleven days after administration. Results showed significantly increased counts of lactobacilli on the jejunum mucosa and high levels of all those strains that remained eleven days after 
administration (Johansson et al., 1993). Colonization experiments in mice, also showed that the number of lactobacilli detected in samples collected from various regions of the gastrointestinal tract, two weeks after inoculation, were not statistically significant different, no matter which strain had been used to colonize mice. In addition, it was concluded that bile salt hydrolase production was not an essential attribute for lactobacilli to colonize the murine gastrointestinal tract. Furthermore, the growth rate of mice that consumed a nutritionally balanced diet were not affected by the presence of bile salt hydrolase producing or not lactobacilli in the gastrointestinal tract (Bateup et al., 1995). The capacity of different lactobacillus strains to grow in and adhere to small intestinal mucus as well as the characteristics of binding was studied. It was shown that six Lactobacillus strains isolated from porcine small intestinal mucosa, one isolated from faeces, one isolated from stomach and one more isolated from human feces, all grew equally well in intestinal mucus extract. Growth was monitored by enumerating the colony forming units. During growth in mucus, a visible precipitation was developed because lactobacilli formed clusters surrounded by mucus. In this study it was observed that when lactobacilli were grown in mucus, the ability to adhere to mucus was reduced from $35 \%$ to $10 \%$ of the adhesion. This could occur because adhesin(s) on the surface of the bacteria were being blocked by receptors or receptors-like components in the mucus (Rojas \& Conway 1996). Adhesion assays of Lactobacillus fermentum 104R (Actually identified as L. reuteri 104R) indicated that this strain adhered to mucus when it was grown in synthetic media. Adhesion data were analyzed by Scatchard plot and it was noted that the binding of lactobacilli to mucus is not mediated by a single adhesin-receptor interaction. The quantitative interpretation of the binding data for this system was not possible to perform because the complexity of the system. These results correlate with other report suggesting that lactobacillus species adhere to intestinal cells via mechanisms which involve different combination of factors on the bacterial cell surface (Greene \& Klaenhammer, 1994). Adhesion promoting compound(s) from L. reuteri $104 \mathrm{R}$ were found in the spent culture medium on the late stationary phase of growth. The spent culture fluid was used to inhibit adhesion to mucus of whole L. reuteri 104R strain, revealing that proteinaceous compound(s) were involved in the binding (Rojas \& Conway, 1996).

\subsection{Lactobacillus adhesins}

Bacteria can have many types of surfaces, including sheaths, S-layers, capsules and walls. In the laboratory certain surface types are usually expressed. For example, E. coli K12 contains only core polysaccharide plus lipid A in its lipopolisaccharide that was why this strain is restricted to a laboratory habitat since it cannot withstand the rigors of a natural environment. This strain possesses only an outer membrane as its surface component surfaces components, but a related strain, K-30, is enclosed in a capsule. Frequently, it is the natural environment and their intrinsic stress that elicit expression of the surface attributes of a bacterium (Costerton, 1988; Brown et al., 1988). A bacterium in its native habitat will often possess a wall overlaid by a multiplicity of superficial layers. After several subcultures in laboratory medium these layers are not longer required and are lost (Costerton, 1988). This surface character could makes difficult the correlation of laboratory studies on adhesins of the bacteria with the In vivo state. Intestinal mucus extract from the small intestine of pig was used for lactobacilli growth and for studying the production and expression of the mucus and mucin adhesion promoting proteins. 
Cell wall of Gram positive bacteria is composed primarily of peptidoglycan, which often contains peptide interbridge and large amounts of teichoic acids (polymers of glycerol or ribitol joined by phosphate groups). Amino acids and sugars are attached to the glycerol and ribitol groups. These molecules are important for maintaining the structure of the wall. Capsules, slims S-layers, sheaths or even pili (fimbriae) can occur as superficial layers above the cell wall. They can occur singly or in combination. Distinction among them is based primarily on their structural attributes (Beveridge, 1989; Beveridge \& Graham, 1991). The term adhesin has been used to denote functions that are involved in one or more of the three following activities: 1) they may promote attachment and then initiate colonization of surface habitats, 2) They may be responsible for the organization of microbial communities and assemblages, and 3) they may be instrumental in promoting cell to cell contact as a phase preceding the transfer of genetic information between cells. The term adhesion has been used to describe the relatively stable, irreversible attachment of bacteria to surfaces, and the term receptor has been used for both known and putative entities on surfaces to which adhesins bind to effect specific adhesion (Jones \& Isaacson, 1984). While there is a considerable amount of information published about proteinaceous bacterial adhesins and their receptors on pathogenic bacteria (Jones \& Isaacson, 1984; Klemm, 1994; Bonazzi \& Cossart, 2011), there are fewer studies on the mechanisms of adhesion of lactobacilli to gastrointestinal mucosa. Adhesion of L. acidophilus to avian intestinal epithelial cells mediated by the crystalline bacterial cell surface layer protein (S-layer) protein was reported (Schneitz \& Lounatma, 1993), and the adhesion to collagen by L. reuteri NCIB 11951 was shown to be mediated by a $29 \mathrm{KDa}$ protein (Aleljung et al., 1994) and to L. crrispatus JCM 5810 was mediated by a $120 \mathrm{KDa}$ S-layer protein (Toba et al., 1995). Another interesting finding was a $32 \mathrm{KDa}$ protein, an aggregation promoting factor on L. plantarum strain 4B2 which increased the frequency of conjugation (Reniero et al., 1992; Reniero et al., 1993). The ability of probiotic bacteria to aggregate should be considered a desirable characteristic because they potentially inhibit adherence of pathogenic bacteria to intestinal mucosa either by direct coaggregation with the pathogens to facilitate clearance, by forming a barrier via self-aggregation or coaggregation with commensal organisms on the intestinal mucosa. Surface proteins from lactobacilli have been reported to be affected by freeze drying (Ray \& Johnson, 1986; Brennan et al., 1986) and by the composition of the culture media (Pavlova et al., 1993; Cook et al., 1988).

Purification and characterization of proteins from lactobacilli which promote the adhesion to mucus have been well studied. The purification of a mucus and mucin adhesion promoting protein (MAPP) from the surface of L. reuteri 104R was performed by using $\mathrm{LiCl}$ (1M). A variety of different agents to extract proteins have been used. EDTA (0.1M), urea $(8 \mathrm{M})$ or $\mathrm{MgCl}_{2}$ have been used to effectively release surface associated material from bacterial cells of various genera. Solutions of detergents such as sodium lauryl sarcosinate, triton X 100 (1\% v/v final concentration), sonication and sodium dodecyl sulphate (SDS, 1\%, $\mathrm{w} / \mathrm{v}$ ) have been shown to be effective in extracting proteins from L. reuteri strain 100-23 (Boot et al., 1993; Chagnaud et al., 1992). Guanidine hydrochloride (4M, GHCl) was used to extract regular arrays from the cell walls of different strains (Masuda \& Kawata, 1983) and an S-layer protein from L. acidophilus ATCC 4356 (Boot et al., 1993). $\mathrm{GHCl}(2 \mathrm{M})$ was used to extract a collagen bindig S-layer protein from L. crispatus JCM 5810 (Toba et al., 1995) while $\mathrm{LiCl}(1 \mathrm{M})$ for $20 \mathrm{~h}$ at $20^{\circ} \mathrm{C}$ after treatment with lysozyme $(2 \mathrm{mg}$ per $\mathrm{ml})$ for $1 \mathrm{~h}$, was used to extract another collagen binding protein from L. reuteri NCIB 11951 (Aleljung et al., 1994). 
The MAPP protein from L. reuteri $104 \mathrm{R}$ was extracted from the surface, by treating the cells after 14-16 h growth in a semi-defined medium (LDM), with $\mathrm{LiCl}(1 \mathrm{M})$ for $1 \mathrm{~h}$ with gently mixing at $4^{\circ} \mathrm{C}$. However, when other lactobacilli strains isolated also from intestinal tract which presented binding to mucus and mucin were treated as above did not show the characteristic band of the MAPP adhesin as it was visualized by western blot with the horse radish peroxidase labeled mucin (Rojas et al., 2002). The adhesion of L. reuteri JCM1081 to HT-29 cells mediated by a cell surface protein was reported. Results showed a 29-kDa surface protein which displays significant peptide sequence similarity to the Lr0793 protein from L. reuteri ATCC55730 (71.1\% identity), whereas the protein Lr0793 is homologous to the $\mathrm{ABC}$ transporter component $\mathrm{CnBP}$, which previously has been described as a collagen binding protein. The $29-\mathrm{kDa}$ surface protein of L. reuteri JCM1081 probably is classified as a member of the ABC transporter family, as well as CnBP from L. reuteri NCIB11951 and MapA from L. reuteri 104R (Wang et al., 2008). The mucus-binding properties of a large collection of L. reuteri strains isolated from a range of vertebrate hosts and the correlation of the adherence of a subset of strains to the presence and expression of MUB was performed by immunodetection, microscopic immunolocalization of MUB on the bacteria, characterization of cell-surface extracts and spent media by gel electrophoresis, Western blotting and mass spectrometry, quantification of mub gene expression by qRT-PCR, cell aggregation and cell-surface MUB quantification. Results revealed that the particular MUB investigated is highly specific to a very small set of closely related strains of L. reuteri. This was observed despite the fact that 17 proteins with a putative MucBP domain were found in the available genomes of L. reuteri. strains 100-23, DSM 20016T, MM2-3, MM4-1, ATCC 55730 and CF48-3A, nine of which were present in the rodent isolate 100-23 (Mackenzie et al., 2010).

\subsection{Adhering probiotic Lactobacillus}

Two requirements have been identified as desirable properties for Lactobacillus to be considered as an effective probiotic microorganism, these include the ability to adhere (Reid, 1999), and then to consequently colonize mucous surfaces. Mucus layer is the first physical barrier to host-cell stimulation by bacteria in the gut. Adhesion to mucus is therefore the first step required for probiotic organisms to interact with host cells and elicit any particular response. Adherence to intestinal mucus has been associated to competitive exclusion of pathogens (Gueimonde et al., 2006; Lee et al., 2008) considering it as a critical event for colonization not only for lactobacilli but also for pathogenic bacteria (Beachey, 1981; Soto \& Hultgren, 1999). In the gastrointestinal tract, mucus is the outermost luminal layer, and is the first intestinal component of surface that microorganisms are likely to contact before they reach epithelial cells. Mackie (Mackie et al., 1999) suggested that during a colonization event, bacterial population remains stable in size, with no need of periodic reintroduction of bacteria by oral doses. This implies that colonizing bacteria multiply in a given intestinal niche at a rate that equals or exceeds their rate of washout or elimination from the intestinal site. However, in practical terms it is well known that external factors can arise such as antibiotic treatments or a change in the nutritional regime that can disrupt the equilibrium of the normal bacterial population (Jernberg et al., 2005). In these cases, it is necessary to supplement the feed with probiotics to restore the balance. Therefore, the ability to replicate in mucus represents an important parameter to evaluate in potential probiotic strains. 
Additionally, it is recognized that resistance of potential probiotic to bile salts is a testable and is a necessary property (Moser \& Savage, 2001).

The mechanisms used by lactobacilli to recognize and adhere to gastrointestinal components, until now is not completely understood. Protein and carbohydrate play an important role in mediating the adhesion to mucosal and or epithelial host surfaces. Some cell-surface biomolecules as exopolysaccharides and proteins have been recognized by their ability to bind gastrointestinal components (Vélez et al., 2007; Rojas et al., 2002; Sun et al., 2007). The best characterized are proteins present in the surface of lactobacilli that can be attached covalently or not to the cell wall (Vélez et al., 2007). Recently, proteins that adhere to mucus or mucins have been described and characterized. Adhering protein molecules characterized from Lactobacillus are Mucus-binding protein (Mub) of L. reuteri 1063 (Roos \& Jonsson, 2002), the lectine-like mannose-specific adhesin (Msa) of L. plantarum WCFS1 (Pretzer et al., 2005), the mucus adhesion promoting protein (MAPP or MapA) from $L$. reuteri $104 \mathrm{R}$ reported by its ability to bind porcine mucus and mucin (Rojas et al., 2002) and Caco-2 cells (Miyoshi et al., 2006) and the Mub of L. acidophilus NCFM (Buck et al., 2005). Moreover, two proteins EF-Tu (Elongation Factor-Tu) and GroEL (a class of heat shock protein) of L. johnsonii La1 NCC533 showed abilities to adhere to mucins at specific conditions of pH (Granato et al., 2004; Bergonzelli et al., 2006). Recently a piglet mucus adhesion protein was completely characterized from the potential probiotic L. fermentum strain BCS87 (Macías-Rodríguez et al., 2009).

\subsection{Genes codifying for Lactobacillus adhesins}

Genetic research on Lactobacillus is underway in many laboratories around the world. Research has centered on 1) characterization and construction of vectors based on endogenos Lactobacillus plasmids which are capables to replicateof replicate and express molecules in specific lactobacilli strains, 2) molecular cloning of genes and operons from lactobacilli encoding important metabolic pathways, proteinases and adhesins 3) methods for introduction of genes In vivo and In vitro through conjugation, transfection and transformation (Chassy, 1987), and more recently 4) the global analysis of proteins and genes using the new tools of proteomic and genomic and the data base information of diferent species of Lactobacillus which are in public data bases. The development of cloning systems of Lactobacillus have increased in the last years. Methods for the introduction and stable maintenance of DNA into Lactobacillus are routine now and can be applied to almost any Lactobacillus species. Both broad host-range and narrow host range multi-copy plasmid vectors based on a variety of replicons have become available for the introduction and expression of homologous and heterologous genes (Pouwels \& Leer, 1993). The sequenced genomes of lactobacilli are increasing and their availability might lead to the identification of the adhesin domain containing proteins in other species of Lactobacillus and in the specific functions of this surface proteins. Genes codifying for above adhesins are well known. The cloning and sequencing of the L. reuteri 104R gene encoding the adhesion promoting protein (MAPP) that binds to porcine gastrointestinal mucus was also studied. The sequence revealed one open reading frame consisting of 744 nucleotides corresponding to 244 aminoacids with deduced $\mathrm{pI}$ of 10.57, net charge at $\mathrm{pH} 7$ of 16.23 and a molecular mass of 26.4 KDa. No putative promoter was found, however a start codon (ATG) appeared 6 bases downstream from the beginning of the sequence. The open reading frame ended with stop 
codons in all three reading frames (TGA A TAA T TAA). Computer search of the nucleotide and aminoacid sequences, showed that this adhesin is related to proteins encoding adherence factors from several pathogenic bacteria, as well as amino acid transporter

binding protein precursors (Rojas, 1996; E. Satoh et al., 2000). Expression by real time PCR of the genes $M u b$ and MapA, adhesion-like factor EF-Tu and bacteriocin gene plaA by $L$. plantarum 423 grown in the presence of bile, pancreatin and at low $\mathrm{pH}$, was reported. It was found that under normal physiological concentration of bile and pancreatin, expression of the $M u b$ gene was affected, the MapA gene was over expressed and the EF-Tu gene remained stable, suggesting that whilst the expression of certain mucus genes may be affected by bile and pancreatin, others mucus genes are switched on, enabling the strain to adapt to physiological conditions and adhere to the gastrointestinal tract (Ramiah et al., 2007). To confirm the MapA results will be interesting to search in L. plantarum genome the compete sequence of this gene and find the adhering function in the reported specie or strain. By searching bacterial genome sequences and the UniProt protein data base for potential mucus binding proteins based on the sequence of the Mub domains of L. reuteri and L. plantarum. Boaekhorst et al, 2006. found that MUB domain is variable in size and sequence, making it difficult to determine precise domain boundaries. However the high variability in the number of MUB domain in putative mucus-binding proteins suggested that the MUB domain is often duplicated or deleted in evolution and appears to be only present in lactic acid bacteria, with the highest abundance in lactobacilli of the gastrointestinal tract, fulfilling an important function in host-microbe interactions (Boekhorst et al., 2006). Characterization of 32 Mmubp and 32-mmubp gene from the potential probiotic strain previously isolated from piglet L. fermentum BCS87 was reported (Macías-Rodríguez et al., 2008). In the adhesion of this wild type strain to mucus and mucin, two proteins were identified, one of them, the 32Mmubp was characterized and the gene that codes for it was reported. Results indicate that the gene encoding this adhesin is conserved for L. fermentum. Other results suggested that 32Mmubp is released to the medium, but it could be anchored to cell wall by electrostatic interactions with acidic groups. It was indicated that Mmubp protein is a member of an $\mathrm{ABC}$ transporter system and is part of the OpuAC family. Based on homology and sequence domain search and in a phylogenetic tree with sequences of a seed group of the OpuAC family were shown conserved sequences between prokaryotic proteins of substrate-binding region on $\mathrm{ABC}$ type glycine/betaine transport systems. Some members of the corresponding taxa having similar ecological niches to those occupied by lactobacilli (gastrointestinal and respiratory tracts), i.e. Helicobacter pylori and Mycobacterium tuberculosis, did not group together suggesting that adhesion mechanisms is not a phylogenetic associated trait (Macías-Rodríguez et al., 2009). Recently was discovered only in the genome of the probiotic Lactobacillus rhamnosus GG, two different pilus fiber in the spaCBA and spaFED gene clusters. Moreover the expression and localization of intact SpaCBA pili on the cell surface of this strain were confirmed by immunoblotting and immunogold-labeled electron microscopy using antiserum specific for the Spa pilin. SpaCBA pilus-mediated binding of L. rhamnosus GG cells to human intestinal mucus was revealed (Kankainen et al., 2009). More recently pilin subunits SpaA, SpaB, SpaD, SpaE and SpaF encoded by genes in the spaCBA and spaFED genes clusters were cloned in E. coli. Recombinant, overproduced proteins were purified and assessment of the adherence to human intestinal mucus was performed. Results suggested that SpaC and 
SpaB may be involved in SpaCBA pilus-mediated adherence to intestinal mucus. It was established that the SpaF minor pilin is the only mucus binding component in the putative SpaFED pilus fiber (von Ossowski et al., 2010). Aggregation promoting factors (Apf) are secreted proteins that have been associated with a diverse number of functional roles in lactobacilli, including self aggregation, coaggregation with other commensal or pathogenic bacteria, maintenance of cell shape and the bridging of conjugal pairs. Genes encoding Apf's have been characterized for several Lactobacillus species, including L. crispatus, L. johnsonii, L. gasseri, L. paracasei and L. coryniformis. Investigation of the functional role of the putative apf gene (LBA0493) in L. acidophilus NCFM by mutational analysis was performed. It was observed that survival rates mutant strain NCK2033 decreased when stationary phase cells were exposed to simulated small intestinal and gastric juices. Furthermore, NCK2033 in the stationary phase showed a reduction of In vitro adherence to Caco- 2 intestinal epithelial cells, mucin glycoproteins and fibronectin. It was suggested that the Apf-like proteins may contributes to the survival of L. acidophilus during transit through the digestive tract and, potentially, participate in the interactions with the host intestinal mucosa (Goh \& Klaenhammer, 2010). The ability to tolerate the toxic levels of bile salts accumulated therein is the essential requirement to survive in the gut and it is generally included among the criteria used for selection of the potential probiotic strains and their application as functional ingredients in foods and nutraceuticals. Expression of bile salt hydrolase and surface proteins were targeted to look at their expression profile in two putative probiotic L. plantarum Lp9 and Lp91, (compared with standard strain CSCC5276) by quantitative real time PCR (RT qPCR). Expression ratio for bsh, mub, mapA and EF-Tu genes under In vitro simulated gut conditions was tested for significance by qBase-Plus software. Amongst the three probiotic strains used in that study, Lp91 showed the highest level of bsh gene expression when the medium was supplemented with $0.01 \%$ mucin along with $1 \%$ of both bile and pancreatin in all the three strains. Results suggested that the expression of mub is a characteristic of not only the specie but could also be strain specific. The highest level of expression of mapA gene was recorded when normal gut conditions (Mucin, $0.01 \%$ and $0.3 \%$ each of bile and pancreatin, $0.3 \%$ supplemented in MRS at $\mathrm{pH}$ 6.5) were used. The relative expression of EF-Tu gene was significantly up-regulated in Lp9 in presence of mucin along at 0.01 and $0.05 \%$, respectively at $\mathrm{pH}$ 7.0. It was concluded that the efficacy of both Lp9 and Lp91 with regards to expression of mub, mapA and EF-Tu was found to be either superior or comparable to that of standard probiotic strain (Duary et al., 2011). To confirm the MapA results in this last report it is important to find if the L. plantarum genome contains this gene to probe then its functionality.

\subsection{Methods for screening mucus or mucin adhering bacteria}

Mucus provides protective functions in the gastrointestinal tract and plays an important role in the adhesion of microorganisms to host surfaces. Mucin glycoprotein forms a framework to which microbial population can adhere, including probiotic Lactobacillus strains. Numerous factors have been shown to influence binding of lactobacilli to mucus in vitro. Experimental methods should be reviewed and compared to get a better understanding of the bacteria-mucosa interaction. The mechanism of this interaction could help to determine the degree of probiotic functionality imparted by adhesion (Tassell et al., 2011). Different methods to measure adhesion to mucus have been reported. Mucus contains about $80 \%$ of carbohydrates which occur as oligosaccharides and most of the glycans are present in 
clusters flanked by naked regions of the protein core (Clamp \& Sheehan, 1978). Since mucins from different sources could be substituted with different oligosaccharides, properties such as the linear charge density could vary considerably. Porcine and rat mucin differ markedly in glycosylation and charge density (Malmsten et al., 1992). This characteristic of mucin, need to be considered when performing experiment to test the interaction between bacteria and mucus or mucin. A common method used to test E. coli adhesion to mucus extract prepared from the large and small intestine of mice involved immobilizing the mucus extracts on polystyrene. Radioactively labeled bacterial suspensions were added to the immobilized mucus compound and after a short inoculation time, the unbound cells were removed and adhesive cells were enumerated by measuring the amount of radioactivity (Laux et al., 1984; Laux, 1986). This method was adapted for studying E. coli adhesion to ileal mucus extracts from pigs (Conway et al., 1990; Blomberg \& Conway, 1989). It has also been used to study the adhesion of L. reuteri $104 \mathrm{R}$ to small intestinal mucus extracts from pig (Rojas \& Conway, 1996). This method still is used with some modifications (Mackenzie et al., 2010), however, it was not suitable for studying adhesion to mucin since it bound poorly to the polystyrene. In a control experiment where horse radish peroxidase labeled mucus and mucin were used, it was shown that mucin adhered to polystyrene a less extent than mucus. These results are consistent with other finding where rat and pig mucin layers on hydrophobic surfaces were studied. It was found by ellipsometry and surface force measurements, by using mica and silica surfaces, that the adsorption equilibrium of rat gastric mucin was reached after 5 hours, however for pig gastric mucin equilibrium it was not reached. It was demonstrated that for such layers, as the repulsive forces become weaker the slower the surfaces are brought together (Malmsten et al., 1992). Dot blot assay, a qualitative In vitro assay to detect the binding of bacterial cell surface components to mucus extracts was developed whereby extracts containing bacterial components and fractionated proteins were immobilized in a solid phase matrix and then blotted with enzymatically labelled mucus (Rojas and Conway, 2001). Results were compared to those obtained using the inhibition assay. In addition, whole cells of Lactobacillus and E. coli were tested in the dot blot assay and results compared with a modification of the method of Laux and coworkers (Conway et al., 1990). The results obtained using the dot blot assay provided further information about the binding of Lactobacillus and E. coli to gastrointestinal mucus, not only because adhesion promoting compounds could be detected in fractionated extracts but also because porcine gastric mucin as well as small intestinal mucus could be used for blotting (Rojas \& Conway, 2001). Other methods have used to study adhesion to mucosa. Cultured cells have been suggested to be the best available models to study intestinal attachment of bacteria and viruses (Coconnier et al., 1997). Particularly, mucus secreting cells could be the best to study Lactobacillus-mucus and mucin interactions. Unfortunately this method has the same limitations as the mucus immobilization method of Laux et al. (Conway et al., 1990) for studing adhesins in soluble extracts.

\subsection{Genetic tools to study the expression of genes encoding adhesins}

The number of genetic tools that have been developed has increased tremendously during the last 20 years. Genetic analysis is made possible for several lactobacilli strains of known probiotic action, such as L. plantarum WCFS1, L. acidophilus NCFM, L. johonsonii NCC533, L. salivarius UCC118, L. reuteri ATCC 55730 and L. rhamnosus GG. Mutant studies are of the 
utmost importance in the unraveling of modes of action of lactobacilli as they can often directly relate genotype to phenotype. Nevertheless the number of currently identified genetic loci hypothesized to encode features supporting probiotic action confirmed by mutant analysis is still limited (Lebeer et al., 2008). Although the availability of genome sequences will certainly advance the field, they need to be complemented with functional studies. Methods that start to be applied for differential gene expression analysis of lactobacilli under relevant conditions are genome-wide comparisons of RNA profiles using microarrays, comparison of protein profiles with two dimensional (2D) difference gel electrophoresis, In vivo expression technology (IVET) using a promoter probe library and differential-display PCR (DD-PCR) (Lebeer et al., 2008).

\section{Materials and methods for screening probiotic potential lactobacilli}

\subsection{Animals}

Newborn piglets (Landrace-Duroc) from a pig farm were maintained with their mothers in maternity cages with grid floors during 23 days before weaned. Piglets received an intramuscular Fe injection (100 mg Fe, VITALECHON DEXTRAN) the second day after birth. Mother's milk fed piglets were given free access to commercial starter feed $(17.5 \%$ crude protein, $2.5 \%$ crude fat, $5 \%$ crude fiber, $12 \%$ moisture, salts, vitamins, and minerals) and water $(<900 \mathrm{ppm}) 2-5$ days before weaning. Maternity cages were maintained at room temperature and warmed up with lamps during the night when needed. To avoid excessive stress caused by high temperatures, piglets were bathed every day at midday.

\subsection{Sampling}

Faecal samples of healthy 23-day-old preweaned piglets from different cages with weights of 10 to $12 \mathrm{Kg}$ were collected in sterile falcon tubes just at the time of defecating and transported to the laboratory at $4{ }^{\circ} \mathrm{C}$. Piglets randomly selected, were sacrificed by a humanitarian method in the laboratory and immediately the small intestine and cecum were removed and sectioned with a sterile dissection kit. These pieces were opened and rinsed with sterile ice-cold phosphate-buffer saline (PBS) $\left(145 \mathrm{mM} \mathrm{NaCl}, 2.87 \mathrm{mM} \mathrm{KH}_{2} \mathrm{PO}_{4}\right.$, and $\left.6.95 \mathrm{mM} \mathrm{K}_{2} \mathrm{HPO}_{4}, \mathrm{pH} 7.2\right)$ in order to remove loosely associated intestinal material. Mucus was then released by gently scraping the small intestine and cecum with a spatula and used to isolate lactic acid bacteria.

\subsection{Isolation of bacteria}

Isolation and characterization of bacteria was previously performed as reported before (Rojas \& Conway, 1996; Macías-Rodríguez et al., 2008) . Briefly, lactic acid bacteria from faeces and from associated small intestine and cecum mucus of healthy preweaned piglets were isolated. Both faecal and mucosal samples were diluted in PBS and serial dilutions were plated on Rogosa SL agar (Difco). Plates were incubated at $37{ }^{\circ} \mathrm{C}$ for $24 \mathrm{~h}$ in an anaerobic jar with a Gaspack system. Counts of colony forming units (CFU) per gram and for $\mathrm{cm}^{2}$ were reported. Colonies from each faecal or mucosal piglet sample were randomly selected from the last dilutions, purified on Rogosa SL plates and grown in MRS broth (Mann, Rogosa and Sharpe, Difco). Aliquots of each strain were kept in $1.5 \mathrm{ml}$ tubes with $50 \%$ of glycerol at $-85^{\circ} \mathrm{C}$. Fresh cultures were used to perform the adhesion assay. 


\begin{tabular}{|c|c|c|c|}
\hline \multirow{2}{*}{ Source } & \multirow{2}{*}{ Strain } & \multirow{2}{*}{$\begin{array}{l}\text { Accession numbers } \\
\text { (16-23S/ 16Sr DNA) }\end{array}$} & $\%$ identity \\
\hline & & & Based on $16 S$ rDNA sequence \\
\hline Faeces & BCS9 & EF113967/ EF113958 & 99\% to Lactobacillus fermentum \\
\hline Faeces & BCS10 & EF113968/ EF113959 & 99\% to Lactobacillus fermentum \\
\hline Faeces & BCS12 & EF113969/ EF113960 & 99\% to Lactobacillus fermentum \\
\hline Faeces & BCS13 & EF113970/ EF113961 & 99\% to Lactobacillus fermentum \\
\hline Faeces & BCS14 & EF113971/ EF113962 & 99\% to Lactobacillus fermentum \\
\hline Faeces & BCS21 & EU547278/ EU547296 & 99\% to Lactobacillus fermentum \\
\hline Faeces & BCS24 & E113972/ EF113963 & $99 \%$ to Lactobacillus fermentum \\
\hline Faeces & BCS25 & EU547279/ EU547297 & 99\% to Lactobacillus fermentum \\
\hline Faeces & BCS27 & EU547280/ EU547298 & 99\% to Lactobacillus fermentum \\
\hline Faeces & BCS30 & EU547281/ EU547299 & 99\% to Lactobacillus fermentum \\
\hline Faeces & BCS36 & EU547282/ EU547300 & $100 \%$ Lactobacillus fermentum \\
\hline Faeces & BCS41 & EU547283/ EU547301 & 100\% Lactobacillus johnsonii; \\
\hline Faeces & BCS46 & EF113973/ EF113964 & $99 \%$ to Lactobacillus fermentum \\
\hline Faeces & BCS68 & EU547284/ EU547302 & $99 \%$ to Lactobacillus vaginalis \\
\hline Faeces & BCS75 & EF113974/ EF113965 & $99 \%$ to Lactobacillus fermentum \\
\hline Faeces & BCS80 & EU547285/ EU547303 & $99 \%$ to Lactobacillus fermentum \\
\hline Faeces & BCS81 & EU547286/ EU547304 & $99 \%$ to Lactobacillus fermentum \\
\hline Faeces & BCS82 & EU547287/ EU547305 & $99 \%$ to Lactobacillus fermentum \\
\hline Faeces & BCS87 & EF113975/ EF113966 & $99 \%$ to Lactobacillus fermentum \\
\hline SI mucus* & BCS113 & EU547288/ EU547306 & $\begin{array}{c}92 \% \text { to Lactobacillus delbrueckii } \\
\text { subsp. bulgaricus }\end{array}$ \\
\hline SI mucus* & BCS125 & EU547289/ EU547307 & $99 \%$ to Lactobacillus crispatus \\
\hline SI mucus* & BCS127 & EU547290/ EU547308 & $99 \%$ to Lactobacillus reuteri \\
\hline SI mucus* & BCS154 & EU547294/ EU547312 & $99 \%$ to Lactobacillus vaginalis \\
\hline C mucus** & BCS134 & EU547291/ EU547309 & $99 \%$ to Lactobacillus reuteri \\
\hline C mucus** & BCS136 & EU547292/ EU547310 & $99 \%$ to Lactobacillus reuteri \\
\hline C mucus** & BCS142 & EU547293/ EU547311 & $99 \%$ to Lactobacillus reuteri \\
\hline C mucus** & BCS159 & EU547294/ EU547313 & $99 \%$ to Lactobacillus reuteri \\
\hline
\end{tabular}

*Intestinal tract mucus, ** Cecum mucus

Table 1. Strains isolated from faeces and mucus of healthy piglets used in this study (Macías-Rodríguez et al., 2008). 


\subsection{Oligonucleotide design and synthesis}

Oligonucleotides used for PCR amplifications were designed with the Primer Select tool of the Laser gene software (Version 5) and synthesized at the Instituto de Biotecnología, UNAM (Mexico). All are listed in Table 2.

\begin{tabular}{|l|l|l|}
\hline $\begin{array}{c}\text { Oligonucleotide } \\
\text { name }\end{array}$ & \multicolumn{1}{c|}{ Orientation } & \multicolumn{1}{c|}{ Sequence } \\
\hline MAP1F & Forward & 5' ATGCCTGCAGGAATCACAA 3' \\
\hline MAP1R & Reverse & 5' AGTAATATCTGCACCGAAGTA 3' \\
\hline MEF7 & Forward & 5' ATTTACGCCCTGGCCCTGGAAAAG-3' \\
\hline MER9 & Reverse & 5' AGAGGGTGTATTTGTTGCCATTGG-3' \\
\hline MAP2F & Forward & 5' TCTTATGCGACCCACAGTTTG 3' \\
\hline MAP2R & Reverse & 5' CTAAGAGCCCCGTCGTTC 3' \\
\hline
\end{tabular}

Table 2. Oligonucleotides used for PCR amplifications

\subsection{PCR amplification of the 32-Mmubp gene}

Amplification of the 32-Mmubp gene of L. fermentum previously reported by (MacíasRodríguez et al., 2009) was performed using as template the chromosomal DNA of Lactobacillus strains previously characterized as potential probiotic by traditional methods (Table 1). A combination of gene specific oligonucleotides for an internal fragment MEF7 and MER9 was used to perform the amplification. The PCR solution contained a final concentration of $1 \times$ Taq polymerase buffer, $3 \mathrm{mmol} \mathrm{l}^{-1} \mathrm{MgCl}_{2}, 0.4 \mathrm{mmol} \mathrm{l}^{-1}$ for each dNTP, 120 pmol of each primer, $250 \mathrm{ng}$ chromosomal DNA and $1 \mathrm{U}$ of Taq DNA polymerase in a total volume of $25 \mu \mathrm{l}$. Amplification reaction was performed in a thermocycler (Perkin-Elmer mod. GeneAmp 2400) with the following temperature program: 1 cycle at $94^{\circ} \mathrm{C}$ for $5 \mathrm{~min} ; 30$ cycles consisted in a denaturation step at $94^{\circ} \mathrm{C}$ for $1 \mathrm{~min}$, an annealing step at $55^{\circ} \mathrm{C}$ for $1 \mathrm{~min}$ and an extension step at $72^{\circ} \mathrm{C}$ for $1 \mathrm{~min}$. A final extension was performed at $72^{\circ} \mathrm{C}$ for $5 \mathrm{~min}$. PCR products were then analyzed in a $1.5 \%$ agarose gel.

\subsection{PCR amplification of the mapp or mapA gene}

Amplification of the gene mapp or mapA (Genebank accession number AJ293860) previously described (Rojas 1996, Satoh et al., 2000 and Miyoshi et al., 2006) was performed using as template the same chromosomal DNA of Lactobacillus strains used for amplification of the $32 \mathrm{Mmubp}$ gene. A combination of gene specific oligonucleotides for an internal fragment of the open reading frame MAP1F and MAP1R (Table 2) was used. The PCR solution contained a final concentration of $1 \times$ Taq polymerase buffer, $3 \mathrm{mmol} \mathrm{MgCl}_{2}, 0.4 \mathrm{mmol}$ for each dNTP, 60 pmol of each primer, $300 \mathrm{ng}$ chromosomal DNA and $1 \mathrm{U}$ of Taq DNA polymerase in a total volume of $25 \mu \mathrm{l}$. Amplification reaction was performed in a thermocycler (Perkin-Elmer mod. GeneAmp 2400) with the following temperature program: 1 cycle at $94^{\circ} \mathrm{C}$ for $5 \mathrm{~min} ; 28$ cycles consisted in a denaturation step at $94^{\circ} \mathrm{C}$ for $1 \mathrm{~min}$, an annealing step at $49^{\circ} \mathrm{C}$ for $1 \mathrm{~min}$ and an extension step at $72^{\circ} \mathrm{C}$ for $2 \mathrm{~min}$. A final extension was performed at $72^{\circ} \mathrm{C}$ for $5 \mathrm{~min}$. PCR products were analyzed in a $1.5 \%$ agarose gel. 


\subsection{PCR amplification of the operon containing the MapA gene}

Polymerase Chain Reactions was performed with primers MAP2F and MAP2R (Table 2) for an internal fragment of the operon containing the mapA gene (Genebank LOCUS AJ293860) using as template the chromosomal DNA of Lactobacillus strains mapA positive. The PCR solution contained a final concentration of $1 \times$ Taq polymerase buffer, $2 \mathrm{mmol}^{\mathrm{MgSO}_{4}}$, $0.4 \mathrm{mmol}$ for each dNTP, $100 \mathrm{pmol}$ of each primer, $300 \mathrm{ng}$ chromosomal DNA and $2 \mathrm{U}$ of Platinum Taq DNA Polymerase (Invitrogene), in a total volume of $25 \mu \mathrm{l}$. Amplification reaction was performed in a thermocycler (Perkin-Elmer mod. GeneAmp 2400) with the following temperature program: 1 cycle at $94^{\circ} \mathrm{C}$ for $5 \mathrm{~min} ; 30$ cycles consisted in a denaturation step at $94^{\circ} \mathrm{C}$ for $1 \mathrm{~min}$, an annealing step at $62^{\circ} \mathrm{C}$ for $1 \mathrm{~min}$ and an extension step at $68^{\circ} \mathrm{C}$ for $2 \mathrm{~min}$. A final extension was performed at $68^{\circ} \mathrm{C}$ for $5 \mathrm{~min}$. PCR products were analyzed in a $1.0 \%$ agarose gel.

\section{Results and discussion}

The association of lactobacilli with the epithelial and mucosal surfaces and their presence in faeces in pigs has been well studied (Rojas \& Conway 1996; Macías-Rodríguez et al., 2008). It was shown that Lactobacillus population in faeces ranged between $10^{7}$ and $10^{9} \mathrm{CFU} \mathrm{gr}^{-1}$. Likewise, in intestinal mucosa, counts of $3.8 \times 10^{6}$ and $3.2 \times 10^{6} \mathrm{CFU}$ per $\mathrm{cm}^{2}$ of small intestine and cecum respectively were reported. Cultivable Lactobacillus strains has been found in similar amounts in faeces and intestinal mucus of pigs that inhabit different environmental conditions, cool countries (Rojas and Conway, 1996) and warm arid coasts (MacíasRodríguez et al., 2008). It was found too that L. fermentum and L. reuteri are the major strains which colonize the gastrointestinal tract of pigs. Therefore the screening of Lactobacillus with probiotic potential for piglets with the ability to interact with the host should be addressed to this species. It has been reported that species of Lactobacillus which colonize humans, differ in number and specie from one region to other in the world. Likewise In vivo trials have been shown that probiotic effect of one strain in one region of the world could produce confused results in other. This finding supports the idea to look for a new generation of specific probiotics for animals and humans inhabiting specific region in the world.

Traditionally the screening of Lactobacillus with probiotic potential involve the isolation and purification of many colonies of lactic acid bacteria, confirmation that correspond to presumptive lactobacilli (grown in selective medium, Gram stain, catalasa reaction, etc), selection according to adhesion profile, growth in mucus, bile salt resistance, growth in broad range of temperature and salt concentration, bacteriocin production, growth and adhesion inhibition of enteropathogens, molecular identification, etc. Previously, more than 150 strains were isolated from mucus and feaces of piglets. Results showed that $64 \%$ of presumptive Lactobacillus presented abilities to grow in the presence of $680 \mathrm{mM}$ of $\mathrm{NaCl}$. Additionally $75 \%$ of the isolates were able to grow at $50{ }^{\circ} \mathrm{C}$. These abilities are important considering that probiotic bacteria are exposed to high temperatures and presence of $\mathrm{NaCl}$ during their technological preparation as pelleted or dried feed for pigs. The adhesion assay of the 164 isolates to porcine mucus and mucin allowed visualize strains that bind mucus or gastric mucin in a qualitative manner. Results indicated that 88 isolates representing $53.7 \%$ of the 164 strains, presented adhesion to both mucus and gastric mucin similar to the positive control L. reuteri 104R, (Rojas et al., 2002). From the total of faecal strains $45 \%$ showed binding ability, whereas from intestinal and cecal mucus strains, 64 and $78 \%$ 
presented adhesion ability respectively. These results showed the highest percentage of adhesive strains in the cecum and intestine compared with faeces. Adhesive strains isolated from faeces could be released to the lumen during the renewal of mucus. Different adhesive abilities between faecal and mucosal strains could be also explained if is considered that microbiota in the intestine differs from that in faeces (Marteau, 2002). Moreover, adhesive properties are strain-dependent and differences exist even if strains were isolated from the same source (Kinoshita et al., 2007).

For molecular identification the most common amplified sequences by PCR are the 16-23S intergenic region and $16 \mathrm{~S}$ rDNA gene. The 27 strains used in this work were identified by these methods. Analysis of $16 \mathrm{~S}$ rDNA gene sequences showed that 17 strains belong to $L$. fermentum specie (between 98 to 100\% identity), one strain to L. johnsonii, 2 strains to L. vaginalis, one strain to L. crispatus and 5 strains to L. reuteri species (Table 1). Except strain BCS113 that showed 92\% identity to 16S rDNA of L. delbrueckii subsp. bulgaricus. These results showed that L. fermentum was predominant in faecal adhesive isolates whereas $L$. reuteri was the principal in mucus of cecum. In small intestinal mucus there was not predominant specie. These observations agree with previously reported by Lin et al. (Lin et al., 2007) and (De Angelis et al., 2006) who found both species in faeces and mucus of pigs. This result confirmed the relevance of these species in the intestinal tract of pigs. Moreover, L. fermentum and L. reuteri species have been reported as good candidates as probiotics (De Angelis et al., 2007; Zoumpopoulou et al., 2008). Another species identified as L. johnsonii, L. delbrueckii subsp. bulgaricus, L. vaginalis and L. crispatus have been reported by their probiotic potential in humans and animals (Chen et al., 2007; Matijasic et al., 2006; Ohashi et al., 2007).

To understand the relevance of surface proteins in the adhesion of Lactobacillus to mucus and mucin, the purification and characterization of the adhesins should be performed. In previous reports proteins have been obtained by treatment with chaotropic agents as $\mathrm{LiCl}$. From the spent, centrifuged growth medium and from soluble cytoplasmic extracts. A western blot assay using labelled mucus and mucin has been usually performed to show the protein bands with their relative molecular weight (MW) and in order to characterize them, N-terminal and internal peptide sequences has been determined. The MAPP adhesin of $L$. reuteri and the Mmubp of L. fermentum have been characterized in that manner (Rojas et al., 2002; Macías-Rodríguez et al., 2008). Recently the mucus-binding proteins (MUBs) have been revealed as one of the effectors molecules involved in mechanisms of the adherence of lactobacilli to the host; $m u b$, or $m u b$-like, genes were found in all of the six genomes of $L$. reuteri that are available but the MUB was only detectable on the cell surface of two highly related isolates when using antibodies that were raised against the protein (Mackenzie et al., 2010).

The complete process to get new strains of probiotic potential lactobacilli has been long and complex. Above a review of the different methods and results used was exposed and the results of a proposal are described.

The strains listed in Table 1 were selected because they were the predominant cultivable lactic acid bacteria in a selective medium (Rogosa agar, DIFCO); attached strongly to mucus and mucin when tested by the Dot Blot adhesion assay; grew in mucus, in presence of bile salt and in a broad range of temperatures. Likewise the molecular identification confirmed that $L$. fermentum and $L$. reuteri were the main isolates with probiotic potential for piglets (Macías-Rodríguez et al., 2008). In addition the genes mapp or mapA of L. reuteri and mmub of 
L. fermentum, which codified for mucus adhesins have been well characterized. Here these genes are described and the results of this proposal are discussed.

\subsection{Amplification and sequencing of the 32-Mmubp encoding gene (32-mmub)}

Primers MEF7 and MER9 were previously deduced from the complete nucleotide sequence of 32-mmub gene. The gene presented an ORF (open reading frame) of 903 bp encoding a predicted primary protein of 300 amino acids. This protein presented a signal peptide of 28 amino acids. Cleavage site between residues 28 and 29 were detected with the Signal P 3.0 prediction software. The prediction of transmembrane helices showed that the first 1 to 7 amino acids are predicted to be inside of the cell whereas residues 7 to 29 could be in the membrane and finally the region encompassing amino acids 30 to 300 could be outside. The mature protein consists of 272 residues with a molecular mass of $29,974 \mathrm{Da}$, an isoelectric point of 9.78 and a positive net charge of 21.22 at $\mathrm{pH}$ 7.0. This adhesin protein showed high identity only to L. fermentum (BAG27284). A search of homology (BLAST) with the genome of L. fermentum IFO 3956 recently published (Morita et al., 2008) showed that 32-Mmubp in L. fermentum BCS87 is part of an $\mathrm{ABC}$ transporter system and belongs to the $\mathrm{PBPb}$ superfamily. It showed to be conserved between prokaryotic protein sequences of substrate binding domains on the ABC-type glycine/betaine transport systems of the OpuAc familiy (PF04069). This family is part of a high-affinity multicomponent binding proteins-dependent transport system involved in bacterial osmoregulation and members of this family are often integral membrane proteins or predicted to be attached to the membrane by a lipid anchor. Some members of the corresponding taxa having similar ecological niches to those occupied by lactobacilli (gastrointestinal and respiratory tracts), i.e. Helicobacter pylori and Mycobacterium tuberculosis, do not group together suggesting that adhesion mechanisms is not a phylogenetic associated trait.

To confirm that 32-Mmubp of L. fermentum BCS87 is specific for this especie, a PCR using the MEF7 and MER9 oligonucleotides was performed. Chromosomal DNA of the 26 adhering strains of Table 1 was used as template to amplify an internal product of 32-mmub gene. PCR products of the same size $(550 \mathrm{bp})$ were observed in L. fermentum strain BCS87 and in all strains which belong to the same specie (Figure 1). Moreover a weak band was also observed in species L. johnsonii BCS41, L. vaginalis strains BCS68 and BCS154, L. delbrueckii subsp. bulgaricus BCS113, L. crispatus BCS125 and L. reuteri strains BCS127, BCS134, BCS136, BCS142 and BCS159 (Figure 1) suggesting 32-mmub gene is conserved in piglets adhesive L. fermentum.

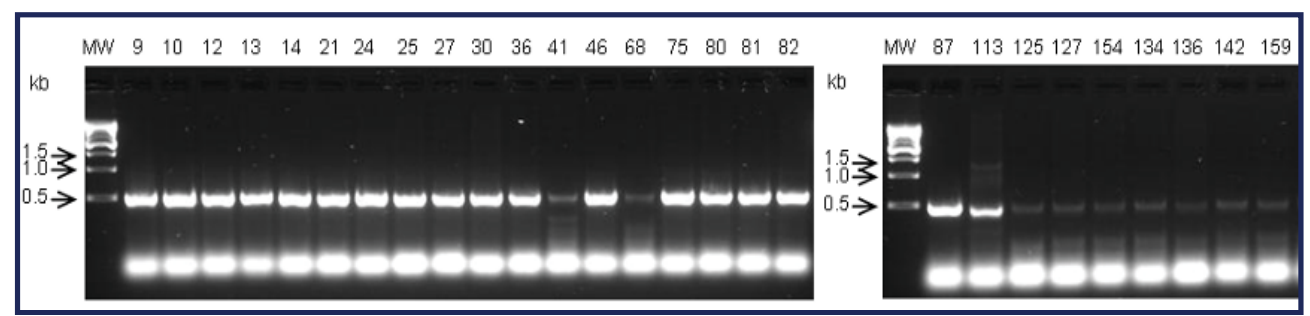

Fig. 1. Amplification of internal fragment of the 32-Mmubp gene in adhesive strains of $L$. fermentum isolated from piglets intestinal tract. Lane MW, Molecular weight. Numbers 9 to 159 represents the identification code for each Lactobacillus strains from Table 1. 


\subsection{Amplification and sequencing of the mapp or mapA gene}

A mucus adhesion promoting protein (MAPP) from L. reuteri 104R was reported (Rojas et al., 2002; Rojas, 1996). The gene encoding this MAPP adhesin (mapp gene) was found by using a PCR strategy were peptide derived oligonucletides were carefully devised and PCR reactions performed using chromosomal DNA of L. reuteri 104R as template. A PCR product was cloning and sequencing. Southern blotting of digested chromosomal DNA with selected enzyme mixtures was performed by using a $189 \mathrm{bp}$ PCR product as a probe. Then a subgenomic DNA library of the hybridized fragment approximately of $4600 \mathrm{bp}$ was running out. DNA fragments in this region were ligated in the pGEM3 vector and cloned in E. coli. Hybridization with the same probe showed a $4500 \mathrm{bp}$ fragment containing the mapp gene. A subcloning and sequencing strategy (Figure 2) was used to determine the nucleotide sequence of the mapp gene. Nucleotide sequence analysis and search of the nucleotide and deduced aminoacid sequenced were searched in different data bases (NCBI). The complete gene mapp was sequenced. The sequence revealed one open reading frame which consists of 744 nucleotides corresponding to a protein of 244 aminoacids with a deduced pI of 10.57

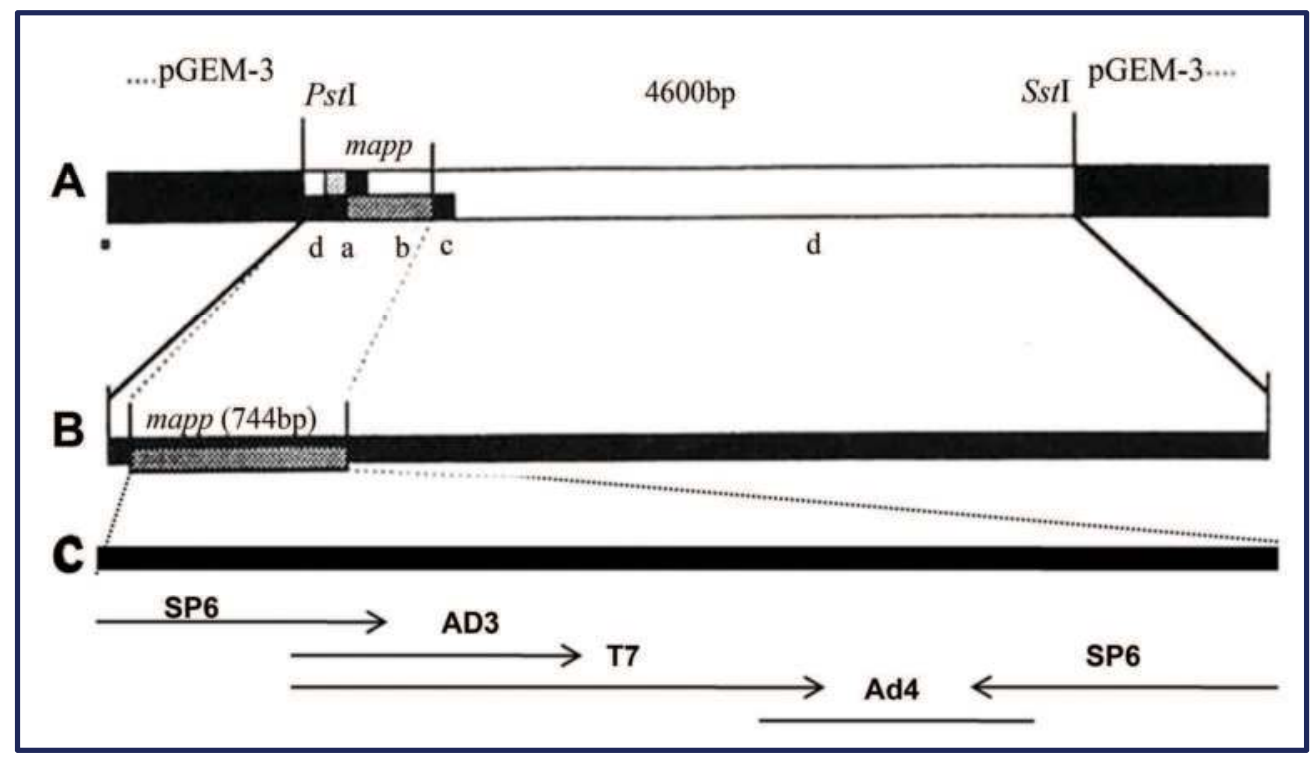

Fig. 2. Schematic drawing of the subcloning and sequencing strategy to determine the nucleotide sequence of the mapp gene. A) The stippled box represents the pGEM-3 vector used to clone the chromosomal DNA fragment $(4500 \mathrm{bp})$ from L. reuteri $104 \mathrm{R}$ and to subclone the fragments a, b, c and d. (inside boxes): a) $189 \mathrm{bp}$, PCR fragment b)610 BglII$B g l I I$ fragment, c) $146 \mathrm{bp} B g l$ II- $B g l$ II fragment and d) vector plus fragment without the two $B g l$ II fragments. B) The largest box represent the $4500 \mathrm{bp}$ fragment and the inside box represent the mapp gene. Universal primers are indicated, arrows indicate nucleotides determined and the heads of the arrow indicate the transcription direction. C) The box represents the $744 \mathrm{bp}$ open reading frame of the mapp gene. Universal and sequence specific primers are indicates, arrows indicate nucleotides determined and the heads of the arrow indicate the transcription direction. 
and a molecular mass of 26380.90 Da. No putative promoter was found, however, a start codon (ATG) was noted 6 bases downstream of the beginning of the sequence and 30 bases upstream of the first $\mathrm{N}$ terminal aminoacid derived codon. The open reading frame ends with stop codons in all three reading frames (TGA A TAA T TAA) (Rojas, 1996).

The mapp gene described in Rojas, 2006, was later reported in Gene Bank as MapA and as part of one operon whose expression is controlled by a mechanism of transcription attenuation involved cysteine, with accession number AJ 293860 (Satoh et al., 2000). The relation between MapA and adhesion of L. reuteri to human intestinal (Caco 2) cells was reported. Quantitative analysis of adhesion of L. reuteri strains to Caco 2 cells showed that various strains bind also intestinal epithelial cells. In addition purified MapA bound to Caco 2 cells and this binding inhibited the adhesion of L. reuteri in a concentration dependent manner. Additionally it was concluded that multiple receptor-like molecules are involved in the MapA binding to Caco 2 cells (Miyoshi et al., 2006).

To confirm that MapA gene is specific for adhesive L. reuteri strains, a PCR using the MAPF1 and MAPR1 oligonucleotides was performed. Chromosomal DNA of the 26 adhering strains of Table 1 was also used as template to amplify the MapA gene. PCR products of the same size were observed only in the L. reuteri strains tested (Figure 3) but not in other species. This result strongly suggests that MapA gene is conserved in piglet adhesive L. reutri strains.

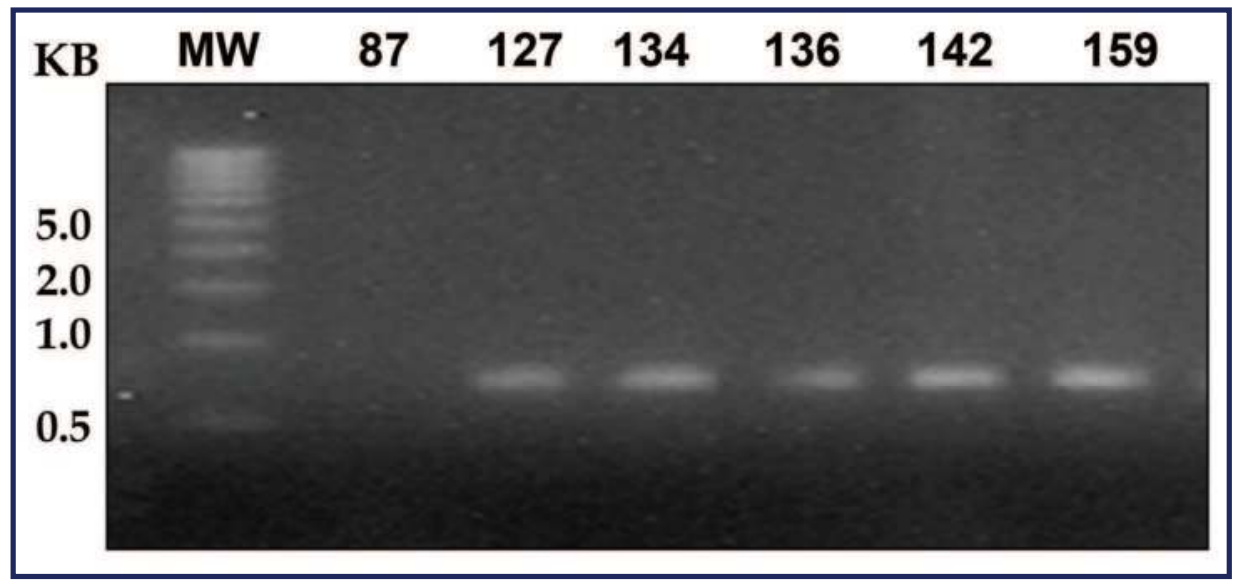

Fig. 3. Amplification of the gene MapA in adhesive L. reuteri strains isolated from piglets intestinal tract. KB Kilobases. MW; Molecular weight. Names on the lanes represent the identification code for each Lactobacillus strains from Table 1.

Expression of the mucus adhesion genes $M u b$ and MapA, adhesion-like factor EF-Tu and bacteriocin gene plaA by L. plantarum 423 was reported. Growth in the presence of bile, pancreatin and at low $\mathrm{pH}$, was studied by real-time PCR. It was found that Mub, MapA and $E F-T u$ were up-regulated in the presence of mucus, proportional to increasing concentrations. Expression of $M u b$ and MapA remained unchanged at $\mathrm{pH} 4.0$, whilst expression of EF-Tu and plaA were up-regulated. Expression of MapA was down-regulated in the presence of $1.0 \mathrm{~g} / \mathrm{l}$ l-cysteine $\mathrm{HCl}$, confirming that the gene is regulated by transcription attenuation that involves cysteine (Ramiah et al., 2007). However the gene and 
operon MapA were not found in L. plantarum by a nucleotide data base search in blastn suite (NCBI). However results in this work suggested that functional MapA gene is specific for at least adhesive $L$. reuteri strains.

Mucus-binding proteins (MUBs) are molecules involved in mechanisms of the adherence of lactobacilli to the host (Roos \& Jonsson, 2002). It was suggested that MUB domain is an LAB -specific functional unit that performs its task in various domain contexts and could fulfils an important role in host-microbe interactions in the gastrointestinal tract (Boekhorst et al., 2006). Recently was reported that in spite that $m u b$, or $m u b$-like, genes are found in all of the six genomes of $L$. reuteri and further demonstrated that MUB and MUB-like proteins are present in many L. reuteri isolates, MUB was only detectable on the cell surface of two highly related isolates when using antibodies that were raised against the protein. There was considerable variation in quantitative mucus adhesion in vitro among L. reuteri strains, showing a high genetic heterogeneity among strains (Mackenzie et al., 2010). Different results were observed for the MapA gene which was present in all the adhesive L. reuteri strains used to amplify this gene.

Recently was reported a well-defined degradation product with antimicrobial activity obtained from the mucus adhesion-promoting protein (MapA) termed AP48-MapA from $L$. reuteri strain. The peptide was purified and characterized. This finding gave a new perspective on how some probiotic bacteria may successfully compete in this environment and thereby contribute to a healthy microbiota (Bøhle et al., 2010). This finding correlate with a report where trypsin digestion of the MapA protein resulted in peptides that bound to mucin suggesting that MapA protein could be involved in colonization of the intestinal mucosa of piglet, since the adhesive capacity could be retained in the intestinal mieleu (Rojas et al., 2002).

To find if L. reuteri strains which contain the MapA gene present the same operon as strain 104R, amplification was run out (Figure 4).

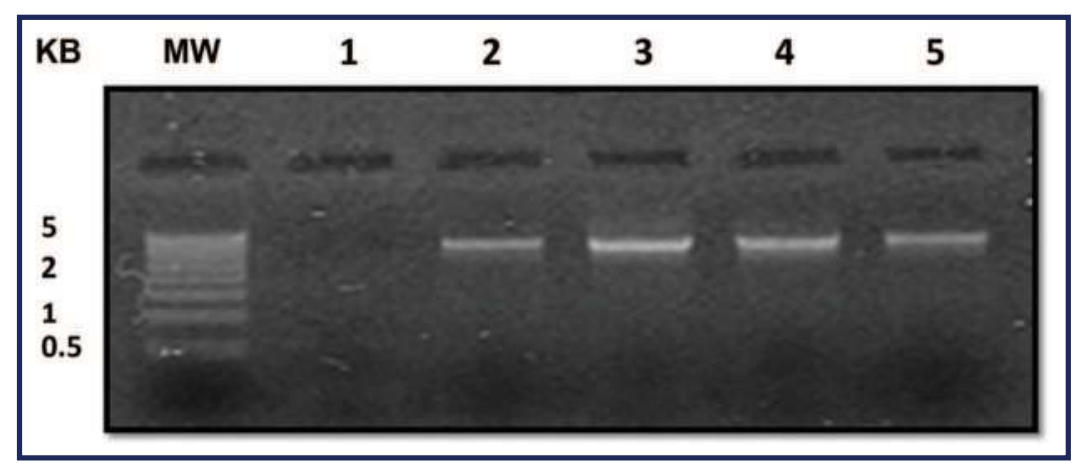

Fig. 4. Amplification of the MapA operon $(3.9 \mathrm{~Kb})$ from different adhesive $L$. reuteri strains isolated from piglets intestinal tract. Lane MW) 500-5000 bp ladder lane 1) Control strain, $L$. fermentum BCS87 lane 2) L. reuteri BCS136, lane 3) L. reuteri BCS127, lane 4) L. reuteri BCS159 and lane 5) L. reuteri BCS142

These results together with the review of adhesins from L. fermentum and L. reuteri and their genes indicate that Mmubp and MapA genes are conserved in these species, at least in 
adhesive strains isolated from intestinal tract of piglets. In Addition these strains are considered the main Lactobacillus species which colonize the intestinal tract of piglets. Therefore the traditional methods for screening new probiotic strains for piglets could be reduced as described.

Take faeces and intestinal tract mucus samples from healthy piglets and make a viable count in a selective medium (Rogosa Agar, DIFCO). Incubate at $36^{\circ} \mathrm{C}$ in anaerobic conditions for 24-48 $\mathrm{h}$ and select colonies from the plates with the more diluted samples to grow and purify the DNA. Perform a PCR reaction using the specific primers for the Mmub and MapA genes. Strains which amplify a fragment with the size mentioned above should be $L$. fermentum for the Mmub gene and L. reuteri for the MapA gene.

\section{Conclusion}

Bacteria cultivated in the laboratory for long time could mutate and lost probiotic attributes, therefore it is important to look for an easy strategy to routinely screening for probiotics. Screening for new probiotic Lactobacillus fermentum and Lactobacillus reuteri, which are the dominant microbiota in healthy piglets and present the ability to adhere the intestinal tract mucus is described in this chapter. The main advantage of this method is the expend time.

\section{Acknowledgment}

This study was supported by Universidad Autónoma de Baja California Sur, México and Conacyt, Project No. 29410-B

\section{References}

Aleljung, P. et al., 1991. Collagen Binding by Lactobacilli. Current Microbiology, 23, pp.33-38.

Aleljung, P. et al., 1994. Purification of collagen-binding proteins of Lactobacillus reuteri NCIB 11951. Current Microbiology, 28, pp.231-236.

Ashenafi, M., 2005. Growth of Listeria monocytogenes in fermenting tempeh made of various beans and its inhibition by Lactobacillus plantarum. Food Microbiology, 8(4), pp.19911991.

Bateup, J.M. et al., 1995. Comparison of Lactobacillus strains with respect to bile salt hydrolase activity, colonization of the gastrointestinal tract, and growth rate of the murine host. Applied and Environmental Microbiology, 61(3), pp.1147-11499.

Beachey, E.H., 1981. Bacterial adherence: Adhesin-receptor interactions mediating the attachment of bacteria to mucosal surface. Journal of Infectious Diseases., 143, pp.325345.

Bergonzelli, G.E. et al., 2006. GroEL of Lactobacillus johnsonii La1 ( NCC 533 ) is cell surface associated: potential role in interactions with the host and the gastric pathogen Helicobacter pylori. Infection and immunity, 74(1), pp.425-434.

Beveridge, T.J., 1989. Role of cellular design in bacterial metal accumulation and mineralization. Annual Review of Microbiology, 43, pp.147-171.

Beveridge, T.J. \& Graham, L.L., 1991. Surface layers of bacteria. Microbiological Reviews, 55(4), pp.684-705.

Bibel, D.J., 1988. Elie Metchnikoff's Bacillus of long life. ASM News, 54(12), pp.661-665. 
Blomberg, L. \& Conway, P L, 1989. An In vitro study of ileal colonisation resistance to Escherichia coli K88 to piglet ileal mucus by Lactobacillus spp. Microbial Ecology in Health and Disease, 2, pp.285-291.

Boekhorst, J. et al., 2006. Comparative analysis of proteins with a mucus-binding domain found exclusively in lactic acid bacteria. Microbiology (Reading, England), 152(Pt 1), pp.273-80.

Bonazzi, M. \& Cossart, P., 2011. Host-pathogen interactions: Impenetrable barriers or entry portals? The role of cell-cell adhesion during infection. The Journal of Cell Biology, 195(3), pp.349-358.

Boot, H.J. et al., 1993. S-Layer protein of Lactobacillus acidophilus ATCC 4356: purification, expression in Escherichia coli, and nucleotide sequence of the corresponding gene. Journal of bacteriology, 175(19), pp.6089-6096.

Brennan, M. et al., 1986. Cellular damage in dried Lactobacillus acidophilus. Journal of Food Protection, 49, pp.47-53.

Brown, M.R.W., Anwar, H. \& Casterton, J.W., 1988. Surface antigens In vivo: a mirror for vaccin development. Canadian Journal of Microbiology, 34, pp.494-498.

Buck, B.L. et al., 2005. Functional Analysis of Putative Adhesion Factors in Lactobacillus acidophilus NCFM. Applied and Environmental Microbiology, 71(12), pp.8344-8351.

Bøhle, L.A. et al., 2010. Specific degradation of the mucus adhesion-promoting protein (MapA) of Lactobacillus reuteri to an antimicrobial peptide. Applied and Environmental Microbiology, 76(21), pp.7306-9.

Chagnaud, P., Jenkinnson, H.F. \& Tannock, G. W., 1992. Cell surface associated proteins of gastrointestinal strains of lactobacilli. Microbial Ecology in Health and Disease. 5(3), pp.121-131.

Chassy, B.M., 1987. Pospects for the genetic manipulation of lactobacilli. FEMS Microbiol Rev, 46, pp.297-312.

Chateau N, Castellanos I, D.A., 1993. Distribution of pathogen inhibition in the Lactobacillus isolates of a commercial probiotic consortium. Journal of Applied Bacteriology. 74(1), pp.36-40.

Chen, X. et al., 2007. The S-layer proteins of Lactobacillus crispatus strain ZJ001 is responsible for competitive exclusion against Escherichia coli O157:H7 and Salmonella typhimurium. International Journal of Food Microbiology. 115, pp.307-312.

Chiduwa, G. et al., 2008. Herd dynamics and contribution of indigenous pigs to the livelihoods of rural farmers in a semi-arid area of Zimbabwe. Tropical Animal Health and Production, 40(2), pp.125-36.

Clamp, J.R. \& Sheehan, J.K., 1978. Chemical aspects of mucus. British Medical Bulletin, 34(1), pp.25-41.

Coconnier, M.H., Liévin, V. \& Hudault, S, 1997. Antibacterial effect of the adhering human Lactobacillus acidophilus strain LB. Microbiology, 41(5), pp.1046-1052.

Collado, M.C. et al., 2006. Protection mechanism of probiotic combination against human pathogens: in vitro adhesion to human intestinal mucus. Asia Pacific Journal of Clinical Nutrition. 15(4), pp.570-575.

Conway, P L, Welin, A. \& Cohen, P.S., 1990. Presence of K88-specific receptors in porcine ileal mucus is age dependent. Infection and Immunity, 58(10), pp.3178-3182.

Conway, P L \& Adams, R.F., 1989. Role of erythrosine in the inhibition of adhesion of Lactobacillus fermentum strain 737 to mouse stomach tissue. Journal of General 
Microbiology, 135(5), pp.1167-73. Available at:

http://www.ncbi.nlm.nih.gov/pubmed/2559943.

Cook, R.L., Harris, R.J. \& Reid, G, 1988. Effect of culture media and growth phase on the morphology of lactobacilli and on their ability to adhere to epithelial cells. Current Microbiology, 17, pp.159-166.

Costerton, J.W., 1988. Structure and plasticity at various organization levels in the bacterial cell. Canadian Journal of Microbiology, 34, pp.513-521.

De Angelis, M., et. al., 2006. Selection of potential probiotic lactobacilli from pig feces to be used as additives in pelleted feeding. Research in Microbiology, 157, pp.792-801.

Dixon, J.M.S., 1960. The fate of bacteria in the small intestine. Journal of Pathology EBacterology, 79, pp.131-141.

Duary, R.K., Batish, V.K. \& Grover, S., 2011. Relative gene expression of bile salt hydrolase and surface proteins in two putative indigenous Lactobacillus plantarum strains under In vitro gut conditions. Molecular Biology Reports, DOI: 10.1007/s11033-0111006-9.

Dubos, R., et al., 1965. Indigenous, normal and autochthonous flora of the Gastrointestinal Tract. Journal of Experimental Medicine, 122, pp.67-76.

Fuller, R., 1989. Probiotics in man and animals. Journal of Applied Bacteriology, 66, pp.365-378.

Fuller, R., Barrow, P.A. \& Brooker, M.E., 1978. Bacteria associated with the gastric epithelium of neonatal pigs. Applied and Environmental Microbiology, 35(3), pp.582-591.

Goh, Y.J. \& Klaenhammer, T.R, 2010. Functional roles of aggregation-promoting-like factor in stress tolerance and adherence of Lactobacillus acidophilus NCFM. Applied and Environmental Microbiology, 76(15), pp.5005-12.

Goswami, P.S. et al., 2011. Preliminary investigations of the distribution of Escherichia coli O149 in sows, piglets, and their environment. Canadian Journal of Veterinary Research, 75(1), pp.57-60.

Granato, D. et al., 2004. Cell surface-associated elongation factor Tu mediates the attachment of Lactobacillus johnsonii NCC533 ( La1 ) to human intestinal cells and mucins. Infection and Immunity, 72(4), pp.2160-2169.

Greene, J.D. \& Klaenhammer, T R, 1994. Factors involved in adherence of lactobacilli to human Caco-2 cells. Applied and Environmental Microbiology, 60(12), pp.4487-94.

Guarino, A. et al., 2011. The management of acute diarrhea in children in developed and developing areas: from evidence base to clinical practice. Expert Opinion on Pharmacotherpy, pp.22106840-22106840.

Gueimonde M, Sakata S, Kalliomaki M, Isolauri E, Benno Y, S.S., 2006. Effect of maternal consumption of Lactobacillus GG on transfer and establishment of fecal bifidobacterial microbiota in neonates. Journal of Pediatric Gastroenterology and Nutrition, 42(2), pp.266-270.

Guerrant, R. L., Hughes, J. M., Lima, N. L., Crane, J., 1990. Diarrhea in developed and developing countries: magnitude, special settings, and etiologies. Reviews of Infectious Diseases, 12(1), pp.41-50.

Guilliland, S. E., Morelli, L., R.G., 2001. Health and nutritional properties of probiotics in food including powder milk with live lactic acid bacteria. . In Joint FAO/WHO expert consultation, Cordova Argentina.

H, Kinoshita et al., 2007. Quantitative evaluation of adhesion of lactobacilli isolated from human intestinal tissues to human colonic mucin using surface plasmon resonance (BIACORE assay). Journal of Applied Microbiology, 102, pp.116-123. 
Harris, L. J., et al., 1989. Antimicrobial activity of lactic acid bacteria against Listeria monocytogenes. Journal of Food Protection, 52, pp.384-387.

Henriksson, A.R., Szewzyk, R. \& Conway, P. L., 1991. Characteristics of the adhesive determinants of Lactobacillus fermentum 104. Applied and Environmental Microbiology, 57(2), pp.499-502.

Herías M.V. et al., 1999. Immunomodulatory effects of Lactobacillus plantarum colonizing the intestine of gnotobiotic rats. Clinical E Experimental Immunology, 116, pp.283-290.

Hudault, $S$ et al., 1997. Antagonistic activity exerted In vitro and In vivo by Lactobacillus casei (strain GG) against Salmonella typhimurium C5 infection. Microbiology, 63(2), pp.513518.

Jacobsen, C.N. et al., 1999. Screening of probiotic activities of forty-seven strains of Lactobacillus spp. by In vitro techniques and evaluation of the colonization ability of five selected strains in humans. Applied and Environmental Microbiology, 65(11), pp.4949-56.

Jernberg, C. et al., 2005. Monitoring of antibiotic-induced alterations in the human intestinal microflora and detection of probiotic strains by se of Terminal Restriction Fragment Length Polymorphism. Applied and Environmental Microbiology, 71(1), pp.501-506.

Johansson, M.L. et al., 1993. Administration of different Lactobacillus strains in fermented oatmeal soup: In vivo colonization of human intestinal mucosa and effect on the indigenous flora. Applied and Environmental Microbiology, 59(1), pp.15-20.

Jones, G.W. \& Isaacson, R.E., 1984. Proteinaceous bacterial adhesins and their receptors. Critical Reviews in Microbiology, 10(3), pp.229-260.

Jonsson, E. \& Conway, P.L., 1992. Probiotics for pigs. In R. Fuler, ed. Probiotics, the scientific basis. London: Chapman Press, pp. 260-314.

Kankainen, M. et al., 2009. Comparative genomic analysis of Lactobacillus rhamnosus GG reveals pili containing a human- mucus binding protein. Proceedings of the National Academy of Sciences of the United States of America, 106(40), pp.17193-8.

Kaushik, J.K. et al., 2009. Functional and probiotic attributes of an indigenous isolate of Lactobacillus plantarum. PloS one, 4(12), pp.1-11.

Kawai, Y., Suegara, Y.N. \& Shimohashi, H., 1982. Colonization of lactic acid bacteria isolated from rats and humans in the gastrointestinal tract of rats. Microbiology and Immunology, 26(5), pp.363-373.

Klemm, P., 1994. Fibriae: adhesion, genetics, biogenesis and vaccines Per Klemm, ed., London: CRC Press.

Laux, D.C., 1986. Identification and characterization of mouse small intestine mucosal receptors for Escherichia coli K-12(K88ab). Infection and Immunity, 52(1), pp.18-25.

Laux, D.C., McSweegan, E.F. \& Cohen, P.S., 1984. Adhesion of enterotoxigenic Escherichia coli to immobilized intestinal mucosal preparations: a model for adhesion to mucosal surface components. Journal of Microbiological Methods, 2, pp.27-39.

Lebeer, S., Vanderleyden, J. \& De Keersmaecker, S.C.J., 2008. Genes and molecules of lactobacilli supporting probiotic action. Microbiology and Molecular Biology Reviews, 72(4), pp.728-64.

Lee, N.K. et al., 2008. Screening of Lactobacilli derived from chicken feces and partial characterization of Lactobacillus acidophilus A12 as an animal probiotics. Journal of Microbiology and Biotechnology, 18(2), pp.338-342. 
Lin, W.H. et al., 2007. Different probiotic properties for Lactobacillus fermentum strains isolated from swine and poultry. Anaerobe, 13, pp.107-113.

Ma, Y.L. et al., 2005. Effect of Lactobacillus isolates on the adhesion of pathogens to chicken intestinal mucus in vitro. Letters in Applied Microbiology, 42, pp.369-374.

Mackenzie, D. et al., 2010. Strain-specific diversity of mucus-binding proteins in the adhesion and aggregation properties of Lactobacillus reuteri. Microbiology (Reading, England), 156(Pt 11), pp.3368-78.

Mackie, R.I., Sghir, a \& Gaskins, H.R., 1999. Developmental microbial ecology of the neonatal gastrointestinal tract. The American Journal of Clinical Nutrition, 69(5), p.1035S-1045S.

Macías-Rodríguez, M.E. et al., 2009. Lactobacillus fermentum BCS87 expresses mucus- and mucin-binding proteins on the cell surface. Journal of Applied Microbiology, 107(6), pp.1866-74.

Macías-Rodríguez, M.E. et al., 2008. Potential probiotic Lactobacillus strains for piglets from an arid coast. Annals of Microbiology, 58(4), pp.641-648.

Malmsten, M. et al., 1992. Mucin layers on hydrophobic surfaces studied with ellipsometry and surface force measurements. Journal of Colloid and Interface, 151, pp.579-590.

Marteau, P.R., 2002. Probiotics in clinical conditions. Clinical reviews in Allergy E Immunology, 22(3), pp.255-73. Available at: http://www.ncbi.nlm.nih.gov/pubmed/12043384.

Masuda, K. \& Kawata, T., 1983. Distribution and chemical characterization of regular arrays in the cell walls of strains of the genus Lactobacillus. FEMS Microbiology Letters, 20, pp.145-150.

Matijasic, B., Stojkovic, S. \& Rogelj, I., 2006. Survival and In vivo adhesion of human isolates Lactobacillus gasseri LF221 and K7 in weaned piglets and their effects on coliforms, clostridia and lactobacilli viable counts in faeces and mucosa. Journal of Dairy Research, 73, pp.417-422.

McAllister, J.S., Kurtz, H.J. \& Short, E.C., 1979. Changes in the intestinal flora of young pigs with postweaning diarrhea or edema disease. Journal of Animal Science, 49, pp.868679.

Miyoshi, Y. et al., 2006. A Mucus Adhesion Promoting Protein, MapA, Mediates the Adhesion of Lactobacillus reuteri to Caco-2 Human Intestinal Epithelial Cells. Bioscience, Biotechnology, and Biochemistry, 70(7), pp.1622-1628.

Molin, G., 1993. Numerical taxonomy of Lactobacillus spp. associated with healthy and diseased mucosa of the human intestines. Journal of Applied Bacteriology, 74, pp.314323.

Mondal, D. et al., 2011. Contribution of enteric infection, altered intestinal barrier function, and maternal malnutrition to infant malnutrition in Bangladesh. Clinical Infectious Diseases, doi:10.1093/cid/cir807

Moser, S.A. \& Savage, D.C., 2001. Bile salt hydrolase activity and resistance to toxicity of conjugated bile salts are unrelated properties in Lactobacilli. Applied and Environmental Microbiology, 67(8), pp.3476-3480.

Muralidhara, K.S., 1977. Effect of feeding lactobacilli on the coliform and lactobacillus flora of intestinal tissue and feces from piglets. Journal of Food Protection, 40(5), pp.288-295.

Ohashi, Y. et al., 2007. Stimulation of indigenous lactobacilli by fermented milk prepared with probiotic bacterium, Lactobacillus delbrueckii subsp. bulgaricus strain 2038, in the pigs. Journal of Nutritional Science and Vitaminology (Tokyo) 53:82-86, 53(82-86). 
Oostindjer, M. et al., 2010. Effects of environmental enrichment and loose housing of lactating sows on piglet performance before and after weaning. Journal of Animal Science, 88(11), pp.3554-62.

von Ossowski, I. et al., 2010. Mucosal adhesion properties of the probiotic Lactobacillus rhamnosus GG SpaCBA and SpaFED pilin subunits. Applied and Environmental Microbiology, 76(7), pp.2049-57.

Pavlova, S.I. et al., 1993. Effect of medium composition on the ultrastructure of Lactobacillus strains. Archives of Microbiology, 160, pp.132-136.

Pedersen, K. \& Tannock, G W, 1989. Colonization of the porcine gastrointestinal tract by lactobacilli. Applied and Environmental Microbiology, 55(2), pp.279-83.

Pouwels, P H \& Leer, R J, 1993. Genetics of lactobacilli: Plasmids and gene expression. Antonie van Leeuwenhoek, 64(2), pp.85-107.

Pretzer, G. et al., 2005. Biodiversity-based identification and functional characterization of the mannose-specific adhesin of Lactobacillus plantarum. Journal of Bacteriology, 187(17), pp.6128-6136.

Ramiah, K., van Reenen, C. a \& Dicks, L.M.T., 2007. Expression of the mucus adhesion genes Mub and MapA, adhesion-like factor EF-Tu and bacteriocin gene plaA of Lactobacillus plantarum 423, monitored with real-time PCR. International Journal of Food Microbiology, 116(3), pp.405-409.

Ray, B. \& Johnson, M.C., 1986. Freeze drying injury of surface layer protein and its protection in Lactobacillus acidophilus. CryoLetters, 7, pp.210-217.

Reid, G., 1999. The scientific basis for probiotic strains of Lactobacillus. Applied and Environmental Microbiology, 65(9), pp. 3763-3766.

Reniero, R. et al., 1992. High frequency of conjugation in Lactobacillus mediated by an aggregation-promoting factor. Journal of General Microbiology, 138(4), pp.763-768.

Reniero, R. et al., 1993. Purification of Lactobacillus secreted proteins. Biotechnology Techniques, 7(7), pp.401-406.

Robins-Browne, R.M. \& Levine, M.M., 1981. The fate of ingested lactobacilli in the proximal small intestine. American Journal of Clinical Nutrition, 34, pp.514-519.

Rojas, M \& Conway, P L, 1996. Colonization by lactobacilli of piglet small intestinal mucus. The Journal of Applied Bacteriology, 81(5), pp.474-80.

Rojas, M. and Conway, P., 2001. A dot blot assay for adhesive components relative to probiotics. In R. J. Doyl, ed. Methods of enziyology Vol. 336. Microbial Growth and Biofilms. Part A. Developmental and Molecular Biological Aspects. San Diego, California, U.S.A.: Academic Press, pp. 389-402.

Rojas, M., 1996. Studies on an adhesion promoting protein from Lactobacillus and its role in the colonisation of the gastrointestinal tract. PhD thesis Goteborg University, Goteborg, Sweden. I. Maurilia Rojas, ed., Goteborg: Goteborg University.

Rojas, M., Ascencio, F. \& Conway, P.L., 2002. Purification and characterization of a surface protein from Lactobacillus fermentum 104R that binds to porcine small intestinal mucus and gastric mucin. Applied and Environmental Microbiology, 68(5), pp.23302336.

Roos, S. \& Jonsson, H., 2002. A high-molecular-mass cell-surface protein from Lactobacillus reuteri 1063 adheres to mucus components. Microbiology (Reading, England), 148(Pt 2), pp.433-42. 
Sanders, M.E., 2011. Impact of probiotics on colonizing microbiota of the gut. Journal of Clinical Gastroenterology, 45(5), pp.115-119.

Sarem-Daamerdji, L. et al., 1995. In vitro colonization ability of human colon mucosa by exogenous Lactobacillus strains. FEMS Microbiology Letters, 131(2), pp.133-137.

Satoh, E. et al., 2000. The gene encoding the adhesion promoting protein MapA from Lactobacillus reuteri $104 \mathrm{R}$ is part of one operon whose expression is controlled by a mechanism of transcription attenuation, involving cysteine. Gene Bank Accession Number AJ 293860.

Savage, D C, 1992. Growth phase, cellular hydrophobicity, and adhesion in vitro of lactobacilli colonizing the keratinizing gastric epithelium in the mouse. Applied and Environmental Microbiology, 58(6), pp.1992-5.

Schneitz, C.L. \& Lounatma, K., 1993. Adhesion of Lactobacillus acidophilus to avian intestinal epithelial cells mediated by the crystalline bacterial cell surface layer (S-layer). Journal of Applied Bacteriology, 74, pp.290-294.

Shimizu M, Shimizu Y, K.Y., 1978. Effects of ambient temperatures on induction of transmissible gastroenteritis in feeder pigs. Infection and Immunity, 21, pp.747-752.

Smith, H.W., 1965. Observations on the flora of the alimentary tract of animals and factors affecting its composition. Journal of Pathology Bacteriology, 89, pp.95-122.

Soto, G.E. \& Hultgren, S.J., 1999. Bacterial adhesins: common themes and variations in architecture and assembly. Journal of Bacteriology, 181(4), pp.1059-1071.

Suegara, N. et al., 1975. Behavior of microflora in the rat stomach: adhesion of lactobacilli to the keratinized epithelial cells of the rat stomach In vitro. Infection and Immunity, 12(1), pp.173-179.

Sun, J. et al., 2007. Factors involved in binding of Lactobacillus plantarum Lp6 to rat small intestinal mucus. Letters in Applied Microbiology, 44(1), pp.79-85.

Tannock, G. W., Blumershine, R. \& Archibald, R., 1987. Demonstration of epitheliumassociated microbes in the oesophagus of pigs, cattle, rats and deer. FEMS Microbiology Ecology, 45, pp.199-203.

Tannock, G. W. \& Savage, D. C., 1974. Influences of dietary and environmental stress on microbial populations in the murine gastrointestinal tract. Infection and Immunity, 9(3), pp.591-598.

Van Tassell, M.L. \& Miller, M.J., 2011. Lactobacillus adhesion to mucus. Nutrients, 3(5), pp.613-636.

Thompson-Chagoyán, O.C., Maldonado, J. \& Gil, A., 2007. Colonization and impact of disease and other factors on intestinal microbiota. Digestive Diseases and Sciences, 52(9), pp.2069-2077.

Toba, T. et al., 1995. A Collagen-binding S-Layer protein in Lactobacillus crispatus. Applied and Environmental Microbiology, 61(7), pp.2467-2471.

Vélez, M.P., De Keersmaecker, S.C.J. \& Vanderleyden, J., 2007. Adherence factors of Lactobacillus in the human gastrointestinal tract. FEMS Microbiology Letters, 276(2), pp.140-148.

Wang, B. et al., 2008. Identification of a surface protein from Lactobacillus reuteri JCM1081 that adheres to porcine gastric mucin and human enterocyte-like HT-29 cells. Current Microbiology, 57(1), pp.33-38. 


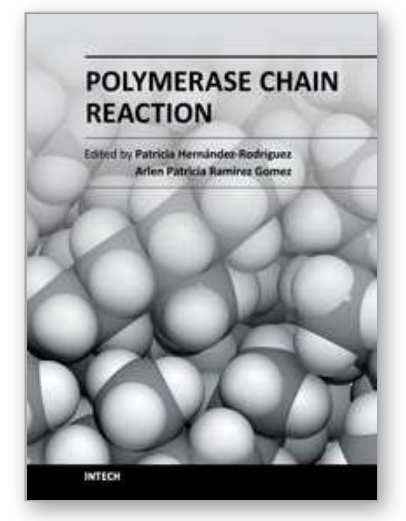

\author{
Polymerase Chain Reaction \\ Edited by Dr Patricia Hernandez-Rodriguez
}

ISBN 978-953-51-0612-8

Hard cover, 566 pages

Publisher InTech

Published online 30, May, 2012

Published in print edition May, 2012

This book is intended to present current concepts in molecular biology with the emphasis on the application to animal, plant and human pathology, in various aspects such as etiology, diagnosis, prognosis, treatment and prevention of diseases as well as the use of these methodologies in understanding the pathophysiology of various diseases that affect living beings.

\title{
How to reference
}

In order to correctly reference this scholarly work, feel free to copy and paste the following:

Maurilia Rojas-Contreras, Maria Esther Macias-Rodriguez and Jose Alfredo Guevara Franco (2012). PCR for Screening Potential Probiotic Lactobacilli for Piglets, Polymerase Chain Reaction, Dr Patricia HernandezRodriguez (Ed.), ISBN: 978-953-51-0612-8, InTech, Available from:

http://www.intechopen.com/books/polymerase-chain-reaction/pcr-for-screening-potential-probiotic-lactobacillifor-piglets

\section{INTECH}

open science | open minds

\author{
InTech Europe \\ University Campus STeP Ri \\ Slavka Krautzeka 83/A \\ 51000 Rijeka, Croatia \\ Phone: +385 (51) 770447 \\ Fax: +385 (51) 686166 \\ www.intechopen.com
}

\author{
InTech China \\ Unit 405, Office Block, Hotel Equatorial Shanghai \\ No.65, Yan An Road (West), Shanghai, 200040, China \\ 中国上海市延安西路65号上海国际贵都大饭店办公楼 405 单元 \\ Phone: +86-21-62489820 \\ Fax: $+86-21-62489821$
}


(C) 2012 The Author(s). Licensee IntechOpen. This is an open access article distributed under the terms of the Creative Commons Attribution 3.0 License, which permits unrestricted use, distribution, and reproduction in any medium, provided the original work is properly cited. 